\title{
New Ultrasound Technologies for Ischemic Heart Disease Assessment and Monitoring in Cardiac Rehabilitation
}

\author{
Antonello D'Andrea ${ }^{1,2, *}$, Simona Sperlongano ${ }^{1}{ }^{(D}$, Mario Pacileo ${ }^{2}$, Elio Venturini ${ }^{3}{ }^{(}$, \\ Gabriella Iannuzzo ${ }^{4}$, Marco Gentile ${ }^{4}\left(\mathbb{C}\right.$, Rossella Sperlongano ${ }^{5}$, Giuseppe Vitale ${ }^{6}(\mathbb{0}$, \\ Marco Maglione ${ }^{7}{ }^{\circ}$, Gennaro Cice ${ }^{8}$, Filippo Maria Sarullo ${ }^{6}$, Anna Di Lorenzo ${ }^{9}$, Carlo Vigorito ${ }^{9}$, \\ Francesco Giallauria ${ }^{9}$ and Eugenio Picano ${ }^{10}$ \\ 1 Unit of Cardiology, Department of Translational Medical Sciences, \\ University of Campania "Luigi Vanvitelli”, Monaldi Hospital, 80131 Naples, Italy; \\ sperlongano.simona@gmail.com \\ 2 Unit of Cardiology and Intensive Coronary Care, “Umberto I" Hospital, 84014 Nocera Inferiore (SA), Italy; \\ m.pacileo@aslsalerno.it \\ 3 Cardiac Rehabilitation Unit, Azienda USL Toscana Nord-Ovest, Cecina Civil Hospital, \\ 57023 Cecina (LI), Italy; vent.elio@tin.it \\ 4 Department of Clinical Medicine and Surgery, Federico II University, 80131 Naples, Italy; \\ gabriella.iannuzzo@unina.it (G.I.); margenti@unina.it (M.G.) \\ 5 Department of Experimental Sciences, University of Campania “Luigi Vanvitelli", 80138 Naples, Italy; \\ rossella.sperlongano@unicampania.it \\ 6 Cardiovascular Rehabilitation Unit, Buccheri La Ferla Fatebenefratelli Hospital, 90123 Palermo, Italy; \\ giuseppevit@hotmail.com (G.V.); fsarullo@neomedia.it (F.M.S.) \\ 7 Esaote, 50127 Florence, Italy; marco.maglione@esaote.com \\ 8 IRCCS San Raffaele Pisana, Via della Pisana 235, 00163 Roma, Italy; gennarocice@hotmail.com \\ 9 Department of Translational Medical Sciences, Federico II University of Naples, 80131 Naples, Italy; \\ dilorenzoanna2@gmail.com (A.D.L.); vigorito@unina.it (C.V.); francesco.giallauria@unina.it (F.G.) \\ 10 CNR Institute of Clinical Physiology Biomedicine Department, 56127 Pisa, Italy; picano@ifc.cnr.it \\ * Correspondence: antonellodandrea@libero.it; Tel.: +39-081-9213111 or +39-081-9213377 or +39-081-9213382; \\ Fax: +39-081-9213361
}

Received: 31 August 2020; Accepted: 26 September 2020; Published: 28 September 2020

\begin{abstract}
Owing to its ease of application, noninvasive nature, and safety, echocardiography is an essential imaging modality to assess cardiac function in patients affected by ischemic heart disease (IHD). Over the past few decades, we have witnessed a continuous series of evolutions in the ultrasound field that have led to the introduction of innovative echocardiographic modalities which allowed to better understand the morphofunctional abnormalities occurring in cardiovascular diseases. This article offers an overview of some of the newest echocardiographic modalities and their promising application in IHD diagnosis, risk stratification, management, and monitoring after cardiac rehabilitation.
\end{abstract}

Keywords: ischemic heart disease (IHD); speckle tracking echocardiography (STE); global longitudinal strain (GLS); left atrial strain; tissue Doppler imaging (TDI); ventricular vortex; color Doppler flow mapping (CDFM); coronary flow reserve (CFR); arterial stiffness; cardiac rehabilitation

\section{Introduction}

Ischemic heart disease (IHD) is the primary global cause of death. Mortality from IHD in Western countries has, however, dramatically decreased during the last decades owing to greater focus on 
primary prevention and improved diagnosis and treatment [1]. IHD diagnostic management includes the evaluation of patient's symptoms and signs, the assessment of electrocardiogram, biochemical and echocardiographic findings, and further diagnostic tests (e.g., coronary computed tomography angiography, stress echocardiography, and single-photon emission computed tomography) if necessary. Once a diagnosis of obstructive coronary artery disease (CAD) has been confirmed, the patient's event risk will be determined, and the appropriate therapy will be chosen [2]. In this context, rest and stress echocardiography play a central role in supporting diagnosis and risk stratification of IHD, providing information about myocardial systolic global and regional function of both left and right ventricle. Transthoracic echocardiography (TTE), because of its ease of application, noninvasive nature, and safety, is the method of choice for assessment of cardiac structure and function. Besides diagnosis, TTE is a useful tool in guiding therapeutic decision-making and in monitoring response to therapy.

Over the last decades, several technological advancements were made in the echocardiographic field, aiming to better understand the morphofunctional abnormalities occurring in cardiovascular diseases. These technologies are still struggling to enter the daily and routine use. This review wants to turn the spotlight on some of the newest cardiac ultrasound imaging technologies highlighting their promising application to the IHD diagnosis, management, and monitoring during cardiac rehabilitation.

\section{Left Ventricular Strain}

During ejection, left ventricular (LV) myocardium undergoes a three-dimensional (3D) deformation, characterized by longitudinal and circumferential shortening, and radial thickening. Added to this is the rotation of the LV around its long axis, i.e., viewed from apex, the apex rotates in anticlockwise direction, whereas the base rotates in the clockwise direction. The movement caused by this opposite rotation is called twist and is crucial for the LV ejection performance. The untwist, which occurs during diastole, generates a suction force that drives the early, rapid diastolic filling of the LV [3]. This complex multi-dimensional deformation during the cardiac cycle is possible owing to the double-helical orientation of LV myocardial fibers, i.e., endocardial helix is more parallel to the LV long axis and is associated primarily with the longitudinal deformation, whereas epicardial helix is responsible primarily for the circumferential shortening. Both subendocardial and subepicardial fibers contribute to radial thickening and to LV rotational movement.

Two-dimensional (2D) speckle tracking echocardiography (STE) is a gray-scale based technique of myocardial deformation imaging, independent from insonation angle, which allows to assess all the above-mentioned components of LV contractile function. The myocardial deformation is quantified as strain or strain rate (SR). Strain is the percentage change in the length of a myocardial segment compared to its resting length; $\mathrm{SR}$ is the rate at which this deformation takes place, expressed as $1 / \mathrm{s}$. Normally, strain and SR have negative values in systole when myocardium shortens and positive values in diastole when myocardium lengthens. The STE software identifies a number of bright speckles generated by the scatter of the ultrasound beam after its interaction with the myocardium and follows them frame-by-frame. Then, through an algorithm, it calculates the magnitude of myocardial deformation in each direction and generates strain and SR curves. The strain analysis is performed on a workstation where gray-scale images are transferred as digital media. Anyway, some of the currently available ultrasound systems offer the possibility of online STE analysis, on the echocardiographic machine itself, even on portable devices.

In order to calculate the LV longitudinal strain, images of high quality from the apical 4-chamber (4CH), 2-chamber $(2 \mathrm{CH})$, and long-axis (LAX) view should be taken, so that the LV occupies most of the sector and is not foreshortened. The optimal gray-scale frame rate should be kept between 30 and 70 frames/s. Three cardiac cycles should be acquired for each view (ECG-gating is mandatory). The images can be transferred to the workstation. It is recommended to start the analysis from the apical long-axis view, where the aortic valve leaflets motion helps to identify the timing of valve closure, that is essential in the deformation study. The endocardial borders are manually traced in the end-systolic frame automatically brought up by the software. A region of interest (ROI), including 
the entire myocardial thickness, is generated by the software and can be manually modified in width. The software then tracks the myocardial speckles frame-by-frame, producing a moving image displaying the tracking during the cardiac cycle. If the tracking seems to be not adequate, the operator can go back and adjust the ROI or select a new ROI. Once the tracking is approved by the operator, the software divides the LV myocardium of the view in analysis in 6 segments, providing segmental and global longitudinal strain, myocardial velocities, and strain curves. The same process must be repeated for the apical 4-chamber and 2-chamber views to obtain strain values for all myocardial segments, their average, and the LV global longitudinal strain (GLS). Some ultrasound systems also provide the bull's eye, which intuitively displays segmental and global peak-systolic longitudinal strain.

A right ventricular (RV) focused 4-chamber view is required to analyze RV strain, whereas short-axis views are required to obtain information about circumferential and radial deformation (basal, mid, and apical levels) and LV twist (basal and apical levels).

Recently, 3D STE has been introduced by applying speckle tracking technologies to 3D echocardiographic images. Images are usually acquired using a matrix-array transducer, from the apical position in a wide-angled acquisition "full-volume" mode. In this mode, a number of wedge-shaped subvolumes are acquired over consecutive cardiac cycles during a single breath hold and stitched together to create one pyramidal volume sample. A major limitation of 3D STE to date is the temporal resolution of the volumetric pyramidal data sets. Usually the rate of acquisition does not exceed 20-30 volumes/s, and, in most cases, to obtain higher temporal resolution, the field of view needs to be considerably narrowed. By fusing 2D speckle tracking information obtained from standard apical $4 \mathrm{CH}, 2 \mathrm{CH}$, and LAX views, $\mathrm{XStrain}^{\mathrm{TM}}$ four-dimensional (4D) aims to make myocardial quantification imaging interpretation easier by the $3 \mathrm{D} / 4 \mathrm{D}$ reconstruction of the $\mathrm{LV}$. The user can freely rotate and zoom the beutel and superimpose the echographic scanning planes to better evaluate the contractility properties of the LV, using a physiological tool to analyze the complex multi-dimensional LV mechanics [4], including a parallel assessment of myocardial regional and global function (Figure 1). By this technique, it is possible to focus the strain analysis on single coronary artery supply regions (Figure 2), allowing better correlations between visual assessment of regional wall motion and quantification of regional deformation.

\section{Role of LV Strain in IHD}

STE is able to detect subclinical LV systolic dysfunction in an early-stage cardiovascular diseases, when LV ejection fraction (LVEF) is still normal. Actually, an isolated impairment of one myocardial layer can be present, compensated by the augmentation of function of the other layers, so that LVEF and overall LV performance remain preserved [5]. For example, in subendocardial ischemia, where there's an involvement of subendocardial fibers, the reduced longitudinal deformation can be compensated by increase in circumferential strain and twist. On the other side, patients with myocardial transmural involvement due to transmural infarction show impairment of both longitudinal and circumferential strain, fall in LVEF, and dilatation of LV cavity.

Strain and SR parameters are significantly reduced in ischemic-segments in patients with acute myocardial infarction (AMI) [6]. Regional longitudinal strain is markedly lower in areas with LGE on cardiac magnetic resonance (CMR) than the normal myocardium, and it gives information on the transmural extent of necrosis [6,7]. A cutoff value of $-11.5 \%$ identified the transmural-infarcted segments with a sensitivity of $75 \%$ and a specificity of $78 \%$ in a study by Cimino et al. [7].

Multilayer longitudinal strain assessed by 2DSTE, in particular endocardial strain, is useful to identify patients with AMI and significant/complex CAD [8-10].

As for the LV, RV peak systolic longitudinal strain is able to predict RV scar and well correlates with scar extent [11]. 


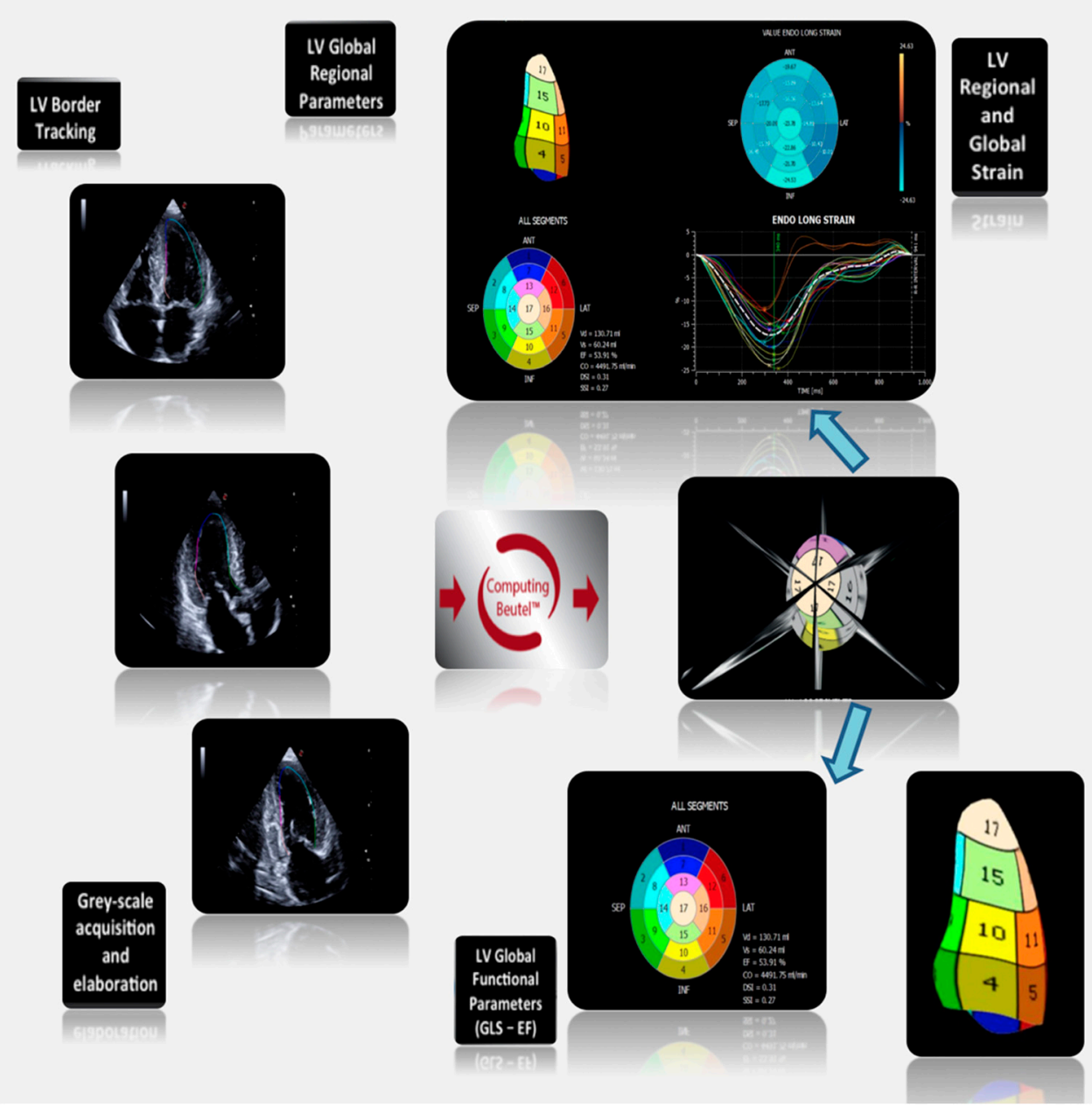

Figure 1. XStrain 4D global LV analysis. At the end of each scanning section, the three apical views are acquired. Then, after left ventricular (LV) endocardial border tracking, the software analyzes LV regional deformation parameters. Finally, the Beutel 3D reconstruction allows quantification of global LV function (global longitudinal strain (GLS) - ejection fraction). XStrain ${ }^{\mathrm{TM}} 4 \mathrm{D}$, done with MyLab X8 eXP-Esaote S.p.A., Florence, Italy.

A

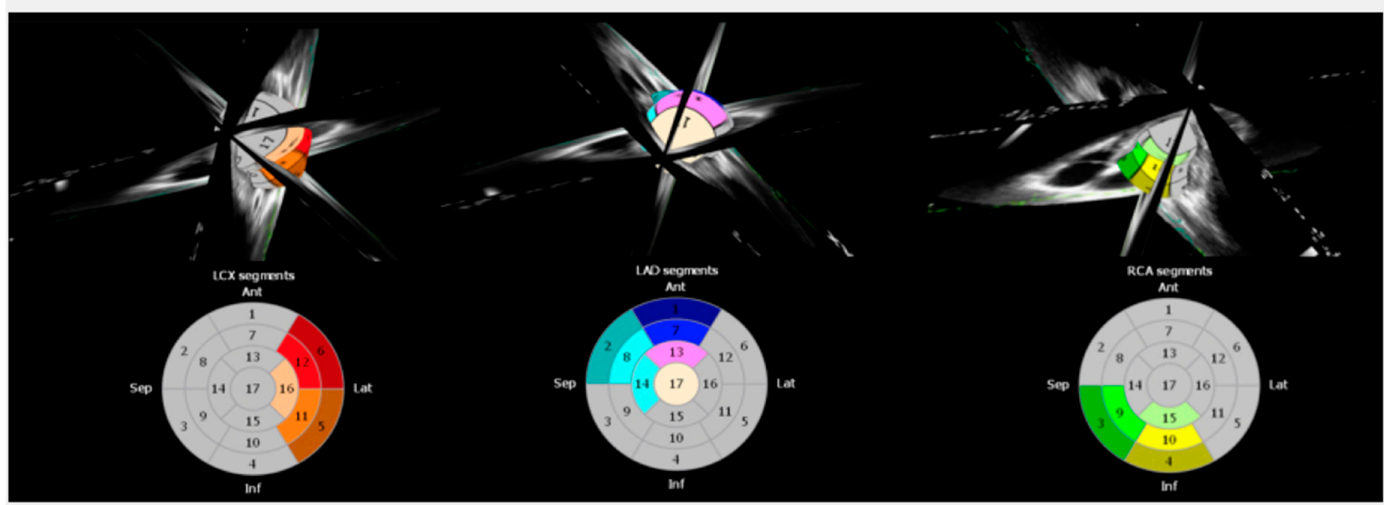

Figure 2. XStrain $4 \mathrm{D}$ regional LV analysis. Left ventricular (LV) regional deformation parameters in three coronary perfusion regions: left circumflex (A), left anterior descending (B), and right coronary artery $(\mathbf{C})$. 
STE adds a prognostic value to the traditional indexes of LV systolic function in both stable and intensive care setting [12]. Longitudinal strain parameters revealed to be independent predictors of death and cardiovascular complications after AMI [13-15].

Peak systolic GLS was also identified as independent predictor of LV function recovery during the follow-up of 12 months after AMI [16]. A low GLS ( $\leq 12 \%)$ after PCI in a population of patients with recent NSTEMI was predictor of negative LV remodeling at follow-up $[17,18]$.

Finally, in a population of patients with ischemic dilated cardiomyopathy, D'Andrea et al. showed that GLS was strongly correlated with the total scar burden assessed by CMR $(r=0.64, p<0.001)$, and was an excellent independent predictor of response to resynchronization therapy $(-10.4 \%$ in nonresponders vs. $-18.4 \%$ in responders, $p<0.001$ ) [19].

\section{Left Atrial Strain}

The main role of left atrium (LA) is to modulate LV filling and cardiovascular performance. For this purpose, LA works as reservoir during ventricular systole, when it receives blood from pulmonary veins and its volume increases, as conduit during early ventricular diastole, passively allowing the passage of blood into the ventricle, and as booster pump during late ventricular diastole, when it actively contracts to complete LV filling. During last years the application of 2DSTE to the LA has been largely investigated in several studies [20-28]. Longitudinal strain and SR curves are generated for each of the 6 atrial segments, obtained from apical 4- and 2-chamber views. Anyway, atrial curves show an opposite morphology than ventricular curves, since that atria and ventricles move in opposite directions during the cardiac cycle. Analogous to the concept of LVGLS, where longitudinal systolic myocardial deformation is quantified, peak atrial longitudinal strain (PALS) detects the maximum elongation of the LA during LV systole, at the end of the reservoir phase. The major determinant of LA expansion is the downward displacement of the LV base toward the apex during LV systole. Therefore, any condition with adverse effect on the LV longitudinal myocardial function will also reduce PALS. Strain is a measure of deformation and is, therefore, dependent on the baseline LA length. Severe LA wall remodeling, like in long-standing atrial fibrillation, leads to progressive LA fibrosis and dilatation, with reduced PALS. The mean value of PALS in healthy subjects is $42 \%$, for LVGLS around $-21 \%$.

\section{Role of LA Strain in IHD}

LA reservoir and conduit functions, respectively, evaluated during systole and early diastole by 2DSTE, are impaired in patients with CAD, even in absence of LA enlargement [29]. LA reservoir dysfunction may reflect a diastolic dysfunction of the LA, likely caused by ischemia. LA conduit dysfunction may be, rather, due to ischemia-related LV compliance impairment during diastole. In patients with CAD and LA enlargement, even LA booster pump function, assessed during late diastole, is significantly impaired, likely due to several factors, such as LV compliance alteration, LV filling pressures elevation, LV systolic dysfunction, and LA myocardial injury. These findings may prove that LA diastolic dysfunction occurs prior to LA systolic dysfunction in patients affected by IHD.

LA strain and SR could be useful in predicting the severity of CAD. Actually, a strong inverse correlation between atrial deformation parameters and severity of coronary stenosis was found [30]. Moreover, LA booster pump function is enhanced in patients with left anterior descending (LAD) occlusion, despite the impairment of reservoir function, probably as response to the increased afterload due to the stiff LV. Conversely, patients with proximal circumflex $(\mathrm{Cx})$ occlusion show LA contractile dysfunction, as the LA is perfused by branches arising from the proximal Cx [30,31].

\section{Tissue Doppler Imaging (TDI)}

TDI is an echocardiographic technique which allows to measure myocardial velocities using Doppler principles. TDI can be performed in three different modalities: pulsed wave (PW), color, and 3D mode [32]. Pulsed wave tissue Doppler imaging (PWTDI) measures the instantaneous regional myocardial peak velocities. A sample volume of $5-7 \mathrm{~mm}$ is placed in the ventricular myocardium, 
adjacent to the mitral annulus, in apical views, in order to obtain longitudinal myocardial velocities which are a good surrogate of LV longitudinal contraction and relaxation. PWTDI has high temporal resolution but does not permit the simultaneous analysis of more myocardial segments. With color TDI, a color-coded box is superimposed to gray-scale 2D or M-mode images, indicating myocardium direction and velocity. Color TDI has higher spatial resolution, it allows simultaneous interrogation of the entire color box, but needs offline quantification of myocardial velocities. Offline velocities obtained by color TDI are approximately $20-25 \%$ lower than those obtained from PWTDI. With 3D TDI, a color-coded TDI is applied to the triplane apical view (simultaneous acquisition of 4-, 2-, and 3-chamber view). Velocities' analysis is performed offline. 3D TDI also allows to calculate LV volumes and $\mathrm{EF}$.

PWTDI represents the cardiac cycle throughout three waveforms: systolic myocardial velocity $\left(\mathrm{S}^{\prime}\right)$ above the baseline, early diastolic myocardial relaxation velocity $\left(\mathrm{e}^{\prime}\right)$ below the baseline, and late diastolic myocardial velocity associated to atrial contraction $\left(a^{\prime}\right)$ below the baseline. Systolic and diastolic time intervals can be obtained using TDI, such as isovolumic contraction time (IVCT), ejection time (ET), and isovolumic relaxation time (IVRT). Finally, the myocardial performance index (MPI) can be calculated as the sum of IVCT and IVRT divided by the ET.

\section{Role of TDI in IHD}

A significant decrease of $S^{\prime}, e^{\prime}$, and a' waves has been observed in patients with IHD, even if cutoff values for maximum systolic and diastolic velocities which detect CAD are still unclear [33].

$S^{\prime}$ velocity can be used to quantify the entity of regional motion impairment. In a systematic review by Agarwal et al., the authors suggest that $S^{\prime}$ velocity may be of help in detecting CAD especially in patients with poor 2D endocardial definition, where the qualitative wall motion analysis can be difficult.

During both acute and chronic ischemia, the phenomenon of postsystolic shortening (PSS) can be quantified by TDI or STE. It is a myocardial shortening that takes place after aortic valve closure and therefore does not contribute to LV ejection. This phenomenon is probably due to the passive recoil from the interaction between ischemic and surrounding nonischemic myocardial segments. Several studies proved that PSS indicates myocardial viability and it is a predictor of systolic recovery in patients with IHD [34-36]. Anyway, data in literature are still conflicting. Terkelsen et al., who assessed PSS by TDI in a STEMI population after revascularization, concluded that PSS was not a marker of cardiac viability because it did not correlate with improvement in strain or wall motion score index (WMSI) at follow-up [37]. Moreover, Brainin et al. found that PSS was an independent predictor of HF in patients following ST-elevation myocardial infarction (STEMI) [38].

\section{Color Doppler Flow Mapping}

Analysis of intracardiac flows represents a way to approach the study of LV function [39]. Normally, during diastole, when blood flow enters the LV from the LA, it gives rise to the formation of two vortices, which rotates around a virtual axis, storing kinetic energy: a main, anterior vortex, which rotates clockwise, and a secondary, posterior vortex, which rotates counterclockwise. The main vortices' determinant is the natural asymmetric geometry of the mitral valve apparatus (the anterior leaflet is longer than the posterior, and the mitral valve orifice is eccentric as compared with the LV axis).

Even if phase-contrast magnetic resonance imaging is the gold standard for measuring blood velocities in heart cavities, some echocardiographic techniques have been developed in order to visualize intracardiac flow, among which is the color Doppler flow mapping (CDFM). The HyperDoppler software is a recent CDFM-based technology that provides different possibilities to represent intracardiac flow data: a flow velocity vector map where velocity vectors are displayed as arrows superimposed on the traditional color Doppler flow images which can be followed frame by frame; a circulation parametric map where vortices are represented as compacted regions in blue (clockwise rotation) or in red (counterclockwise rotation); and a kinetic energy map where the highest level of kinetic energy 
is depicted in red. Normally, intracardiac vortices are visualized on apical long-axis view images (Figure 3).
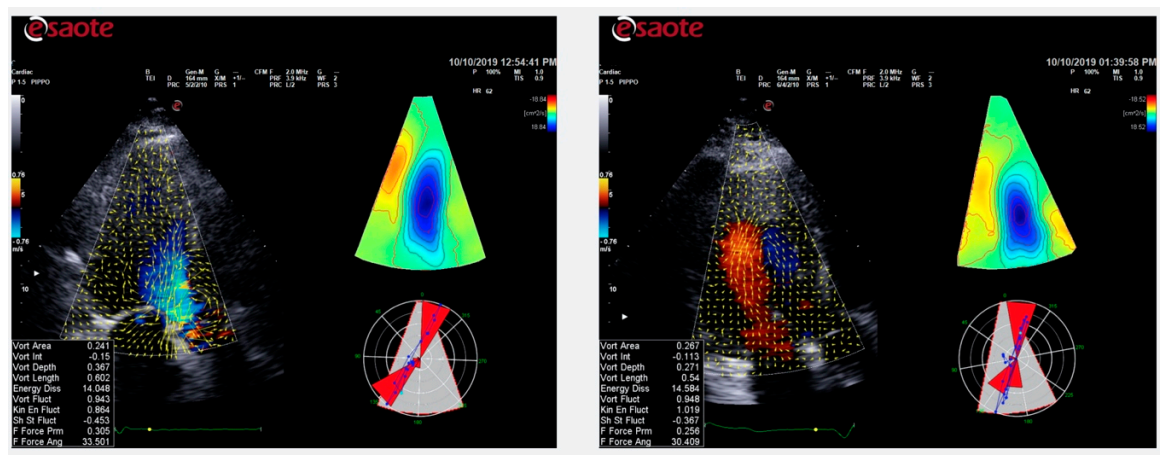

Figure 3. LV vortex analysis. During diastasis, left ventricular (LV) vortex maintains its rotary motion. Subsequently, at the moment of atrial contraction (late filling), a second vortex ring occurs, and the late filling jet combines with the residual early vortex ring. During the isovolumic contraction period, the vortex redirects blood toward the LV outflow tract, with formation of a large anterior vortex across the inflow-outflow region. HyperDoppler software by Esaote S.p.A on MyLab X8 eXP scanner.

Role of CDFM in IHD

The LV vortex formation is the result of an optimal interaction between LV chamber geometry, morphology of the mitral valve apparatus, and normal electrical conduction system, which allows the harmonic contraction of the cardiac walls [39]. If one of these elements is altered, the LV vortex formation is affected too.

In patients with STEMI, kinetic energy dissipation within the LV increases linearly with the increase of LVEF, as the flow turbulence into the LV is higher [40,41]. For the same reason, larger infarctions are associated with a more severe alteration in LV intracavitary blood flow dynamics and a lower dissipation in kinetic energy [42].

Finally, in patients with anterior myocardial infarction, LV vortex flow analysis was useful to identify patients at risk for LV apical thrombus formation [43].

\section{Coronary Flow Reserve}

The evaluation of coronary flow reserve (CFR) is performed by combining transthoracic Doppler echocardiography with vasodilator stress, such as adenosine or dipyridamole. An index of CFR is obtained from the variation between coronary blood flow velocity (CBFV) at baseline and CBFV at the peak of effect of vasodilator. A value of CFR less than 2 is generally considered abnormal. CBFV profile is recorded by PW Doppler, and it is represented by a biphasic wave, with a lower peak during systole and a higher peak during diastole. This pattern derives from the fact that myocardial extravascular resistance is higher in systole, due to the effect of myocardial contraction. The most used parameter in evaluation of CFR is peak diastolic flow, because it is easy to measure, reproducible, and has a closer correlation with CFR measured by Doppler flow wire and positron emission tomography (PET) [44]. The LAD peak diastolic flow is obtained in the mid-distal portion of the coronary artery, from a modified apical $2 \mathrm{CH}$ view, where the transthoracic probe is slightly moved upward and medially, with a little counterclockwise rotation and medial angulation. CFR feasibility of LAD is very high, reaching $98 \%$, and the use of contrast is rarely needed, when the Doppler signal is not appropriate (Figure 4). Noninvasive CFR evaluation is also possible for posterior descending artery (PDA) and Cx, even if with a lower technical feasibility. PDA is assessed from a modified apical $2 \mathrm{CH}$ view showing the posterior interventricular groove, near to coronary sinus ostium. $\mathrm{Cx}$ artery is searched in apical $4 \mathrm{CH}$ view at basal and midportion of $\mathrm{LV}$ lateral wall, and it is the most challenging to evaluate, due to its particular anatomy and the low resolution of the lateral wall. Contrast use may help to increase 
feasibility of CFR in PDA and Cx. Finally, transthoracic Doppler echocardiography may be useful in evaluation of coronary artery bypass graft $(\mathrm{CABG})$ patency, sampling the coronary flow downstream of graft anastomosis.

\section{Role of CFR in IHD}

Stress echocardiography was recently reshaped with the ABCDE protocol: A for asynergy, B for thoracic ultrasound B-lines, C for contractile reserve, D for Doppler-based CFR (in LAD), and E for electrocardiogram-based heart rate reserve (HRR, defined as peak/rest $H R<1.62)$ [45]. ABCDE protocol allows therefore a comprehensive assessment focused on ischemia (A), pulmonary congestion (B), myocardial scar or necrosis (C), coronary microvascular dysfunction (D), and chronotropic incompetence (E) [46].

CFR is a composite measure of coronary macrovascular and microvascular status. A reduced CFR is associated to a negative prognosis in several groups of patients, including those with diabetes mellitus, arterial hypertension, ischemic cardiomyopathy, normal coronaries, and CAD [47]. In patients with IHD, CFR is related to angiographic findings and it is a predictor of the extent and severity of CAD [48].

Recently, the assessment of CFR on TTE has been proposed as method to detect cardiac allograft macro- and microvasculopathy in heart transplant [49]. A recent study showed that CFR is very sensitive for detecting cardiac allograft vasculopathy and increases the diagnostic accuracy of dobutamine stress echocardiography [50].

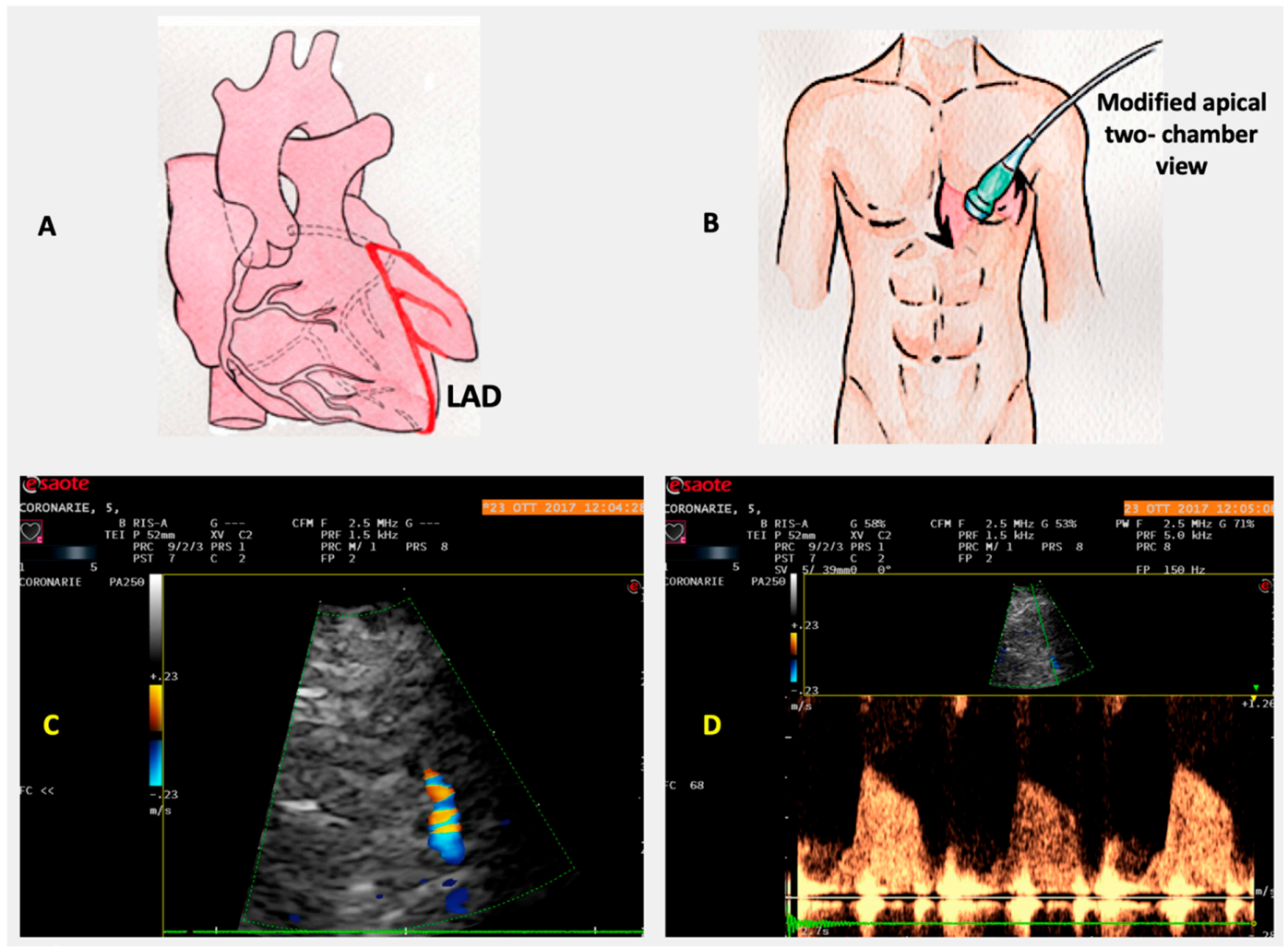

Figure 4. Coronary flow analysis. The distal left anterior descending (LAD) tract is more suitable to investigate coronary microvascular function because it is between large epicardial arteries and microvasculature (A). The acoustic window is, in the left decubitus position, around the midclavicular line in the fourth or fifth intercostal space (B). After detecting by color the LAD image (C), coronary flow by Doppler is represented by a biphasic wave, with a lower peak during systole and a higher peak during diastole, for the effect of myocardial contraction (D). 


\section{Arterial Stiffness}

Vascular aging in large arteries is characterized by structural and functional changes, such as intima-media thickening and "stiffening" [51]. Arterial wall thickening is mainly related to atherosclerotic processes; arterial stiffening, which is the vessel wall's tendency to resist deformation generated by systolic blood pressure during the cardiac cycle, is mainly due to degenerative and calcified processes.

The recently introduced radiofrequency (RF) data technology allows to measure arterial intima-media wall thickness (IMT) and stiffness. All measurements are taken in a selected area of common carotid artery. The blood vessel wall stiffness is expressed in pulse wave velocity (PWV) in meter per second, and is obtained from the brachial blood pressure and the accurate measurements of vessel diameter and distension (change in diameter). For both IMT and stiffness, the operator gets real-time feedback on measurement quality via quality indicators overlaid on the ultrasound image. This real-time feedback gives the operator the possibility to optimize his probe position, in order to obtain a scan plane perpendicular to the wall of the common carotid artery (Figure 5).

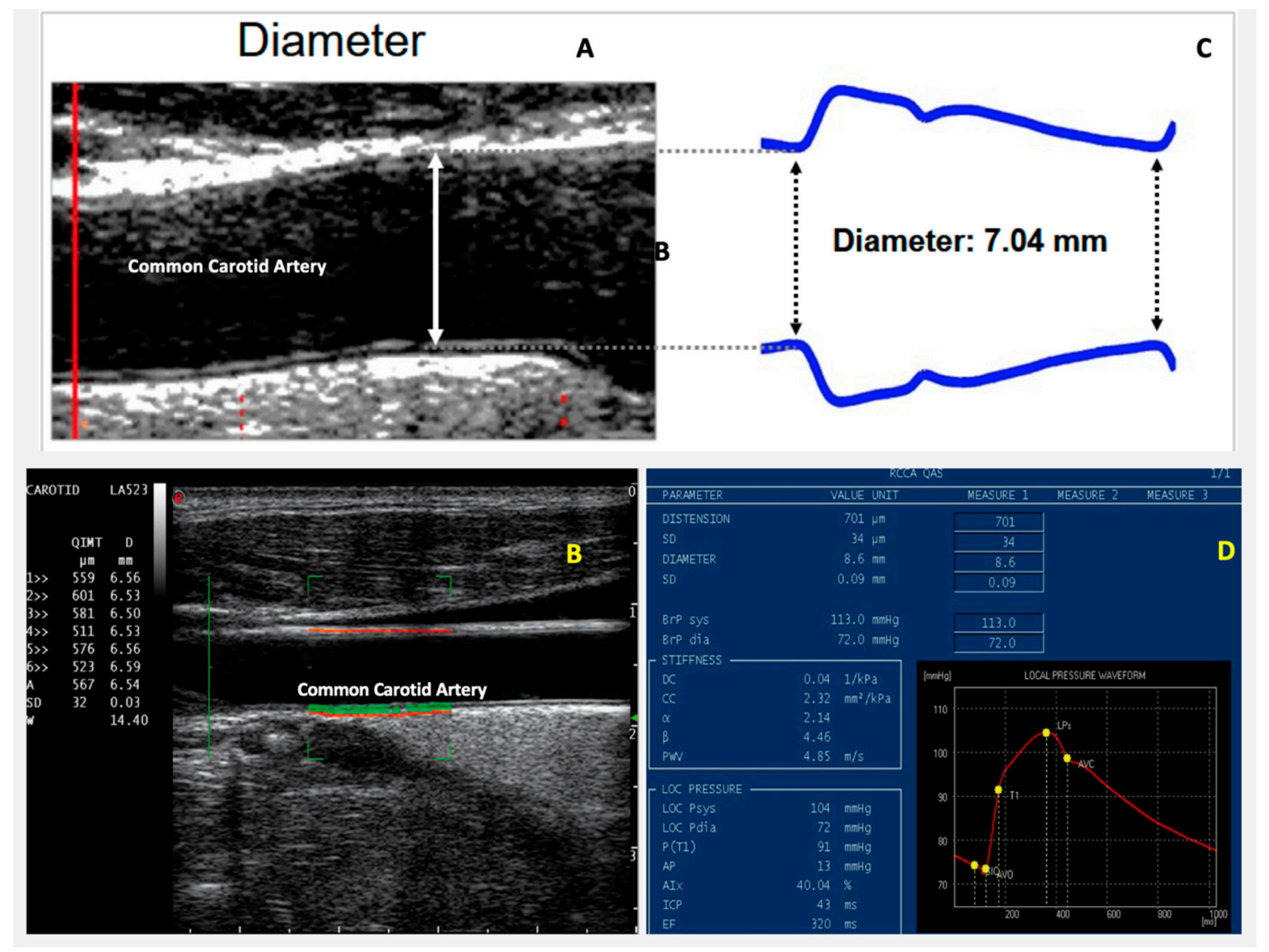

Figure 5. Vascular morphologic and functional analysis. Radio Frequency-Quality Intima Media Thickness ( ${ }^{\mathrm{RF}} \mathrm{QIMT}$ ): during the scanning of the carotid artery a real-time feedback on measurement quality via quality indicators overlaid on the ultrasound image at the position of the vessel wall (orange lines) and the far wall intima layer (green line) (A,B). Radio Frequency Quality Arterial Stiffness ( $\left.{ }^{\mathrm{RF}} \mathrm{QAS}\right)$ targets the measurement of the blood vessel stiffness of a subject in a selected area of investigation. The blood vessel wall stiffness is expressed as pulse wave velocity obtained from brachial blood pressure and the accurate measurements of diameter and change in diameter. Moreover, the local blood pressure at the site of the ultrasound measurement is given $(\mathbf{C}, \mathbf{D}) .{ }^{\mathrm{RF}} \mathrm{QIMT}$ and ${ }^{\mathrm{RF}} \mathrm{QAS}$, respectively-Esaote. 
Role of Arterial Stiffness in IHD

Vascular intima-media thickening and stiffening are correlated to cardiovascular morbidity and mortality [50]. Arterial stiffness plays an important role in systolic blood pressure (BP) and pulse pressure (systolic $\mathrm{BP}$ - diastolic $\mathrm{BP}$ ) increase. Moreover, it can contribute to LV concentric remodeling and hypertrophy, impaired myocardial perfusion, and other changes in LV that form the substrate for systolic and diastolic dysfunction.

PWV is closely linked to the presence of angiographically documented CAD [52]. Moreover, elevated PWV values are associated to an increased risk in cardiovascular events in both patients with and without pre-existing CAD [53-56].

In the EPHESUS study, performed on patients with heart failure and reduced LVEF following AMI, it was shown that an increased aortic stiffness, assessed by PWV, was associated with a negative prognosis and significantly contributed to cardiovascular death [57].

\section{Advantages and Limitations of the New Ultrasound Technologies}

All the above-mentioned echocardiographic technologies have the advantage of being safe, noninvasive, and relatively low cost, and they can be performed bedside. Moreover, they allow to better understand the morphofunctional abnormalities occurring in cardiovascular diseases (Figure 6). Table 1 summarizes specific advantages and limitations of each new technology described in this review.

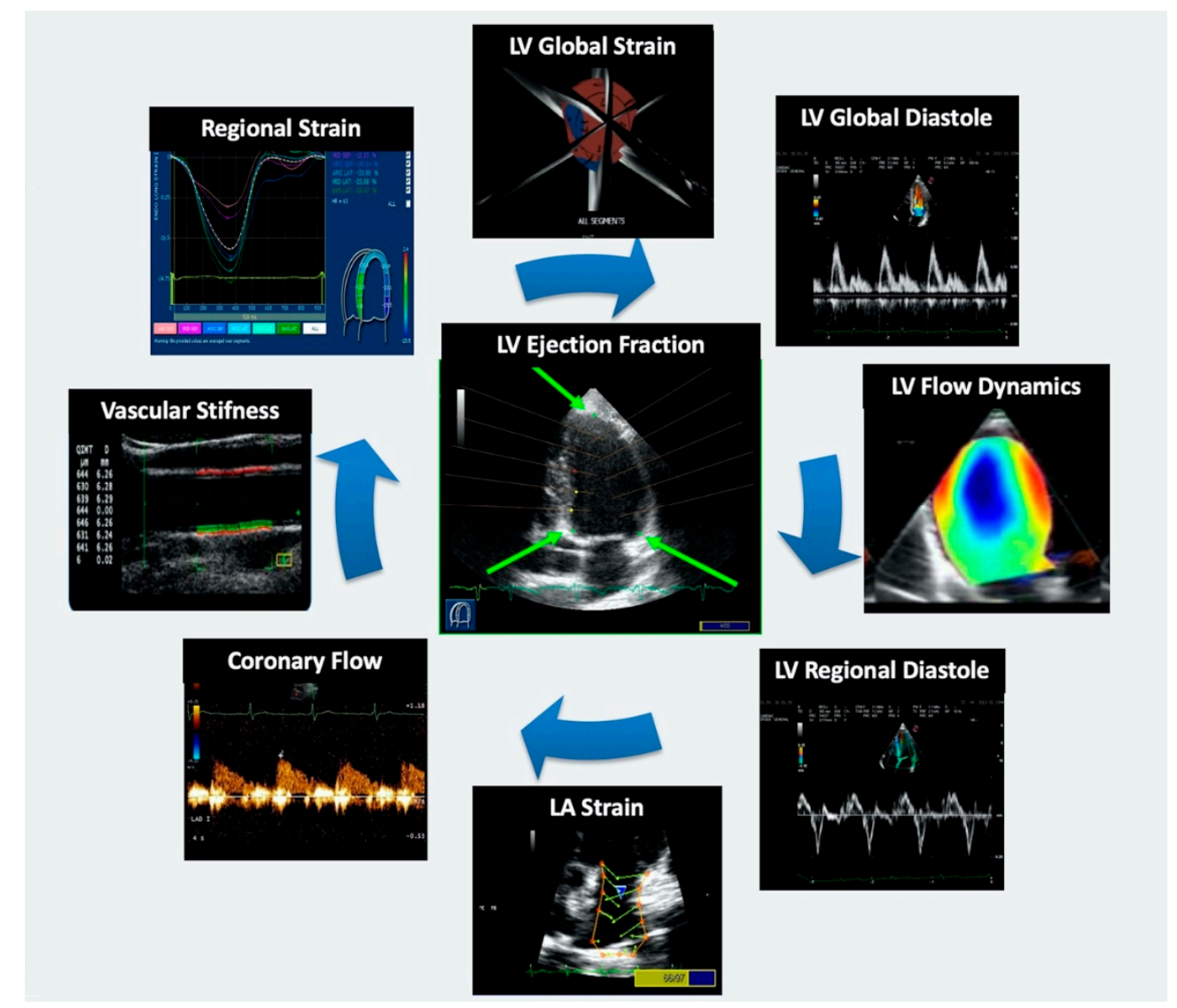

Figure 6. From standard echocardiography to new technologies. The incremental contribution of new echo technologies to provide valuable insights in the pathogenesis of cardiovascular disease, with distinct patterns of myocardial, vascular, and microcirculatory dysfunction. LV: left ventricle. LA: left atrial. 
Table 1. Advantages and limitations of the new ultrasound technologies.

\begin{tabular}{|c|c|c|}
\hline Technology & Advantages & Limitations \\
\hline $\begin{array}{l}\text { Speckle tracking } \\
\text { echocardiography }\end{array}$ & $\begin{array}{ll}\text { - } & \text { Less angle-dependency than TDI } \\
\text { - } & \text { Study of deformation in } \\
\text { any direction }\end{array}$ & 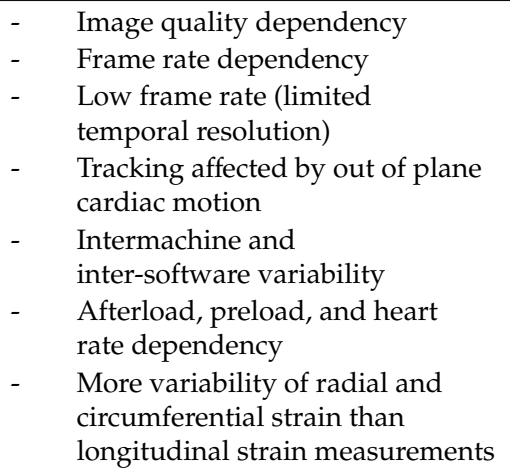 \\
\hline Tissue Doppler imaging & $\begin{array}{ll}\text { - } & \text { Excellent temporal resolution } \\
\text { - } & \text { Online analysis of velocities }\end{array}$ & $\begin{array}{ll}\text { - } & \text { High angle dependency } \\
\text { - } & \text { Size and placement of sample } \\
\text { - } & \text { volume done manually } \\
\text { Deformation assessment in } \\
\text { - } & \text { No direction } \\
\text { - } & \text { Globe interference } \\
& \text { Gloart motion influence }\end{array}$ \\
\hline Color Doppler flow mapping & $\begin{array}{ll}\text { - } & \text { Good spatial 2D resolution } \\
\text { - } & \text { Good time resolution } \\
\text { - } & \text { Accuracy in evaluation of high } \\
\text { - } & \text { flow velocity } \\
\text { - } & \text { Contrast medium not required } \\
& \text { Short processing time }\end{array}$ & $\begin{array}{ll}\text { - } & \text { Underestimation of low } \\
\text { flow velocity } \\
\text { - } & \text { Reconstruction of velocities } \\
\text { perpendicular to beam direction } & \text { Acoustic window dependency } \\
\text { - } & \text { Nonvalidated vs. the gold } \\
& \text { standard (magnetic resonance) }\end{array}$ \\
\hline Coronary flow reserve & $\begin{array}{l}\text { - High accuracy and reproducibility } \\
\text { for LAD } \\
\text { - Contrast medium rarely needed } \\
\text { for LAD } \\
\text { - Combined assessment of coronary } \\
\text { flow and wall motion }\end{array}$ & $\begin{array}{ll}\text { - } & \text { Limited sites of coronary detection } \\
\text { - } & \text { Lower feasibility for posterior } \\
\text { interventricular artery and } & \\
\text { circumflex artery } \\
\text { - } & \text { Angle dependency } \\
\text { - } & \text { Artifacts interference }\end{array}$ \\
\hline Carotid stiffness & $\begin{array}{ll}\text { - } & \text { Good accuracy and reproducibility } \\
\text { - } & \text { Early detection of } \\
\text { cardiovascular damage }\end{array}$ & $\begin{array}{ll}- & \text { Limited diffusion } \\
- & \text { Few studies on large populations }\end{array}$ \\
\hline
\end{tabular}

TDI: tissue doppler imaging; LAD: left anterior descending; 2D: Two-dimensional.

\section{Cardiac Rehabilitation and New Echocardiographic Technologies}

Exercise-based cardiac rehabilitation (CR) in patients affected by CAD increases functional capacity and reduces total and cardiovascular morbidity and mortality [58-62]. A role in this improvement induced by exercise, may be played by reverse LV remodeling characterized by reduced LV volumes and increased LV ejection [63]. Echocardiography is a pivotal tool to evaluate LV stroke volume (SV), cardiac output (CO), and EF, even compared to other noninvasive techniques. A recent study by Gonzalez-Represas and Mourot proved that tonometry and impedancemetry overestimate absolute $\mathrm{SV}$ and $\mathrm{CO}$ values when compared to echo, and they are not useful to reliably track changes of these parameters in CAD patients after a CR program [64]. Traditional echocardiographic indexes should be desirably integrated with the ones deriving from new ultrasound technology. For instance, LVEF alone does not well define LV global systolic function, it is less sensitive for the detection of subclinical contractility changes, and it does not allow every time to recognize the passive motion of myocardial segments which are dragged by adjacent normal segments. The assessment of LV mechanics, with its 3D deformation and rotation, through STE may help to better quantify the functional LV reverse remodeling after MI. McGregor et al. showed that LV twist and twist velocity were significantly reduced in patients with MI who underwent $\mathrm{CR}$ exercise training than nonexercised patients, data which may 
indicate increased systolic efficiency, greater "twist reserve," and so, a favorable adaptation of the LV compromised by MI [65]. GLS was unaffected by exercise training in the study carried out by McGregor et al. Conversely, other studies showed that GLS and radial strain improved in patients who underwent exercise training after MI when compared to patients with MI and without CR [66,67]. Post-MI CR seems to have favorable effects also on LA function evaluated by STE [68]. The positive LA remodeling induced by CR may protect patients from atrial arrhythmias, which increase the risk of stroke and all cause of mortality after acute MI.

Data regarding the clinical application of intracardiac flow analysis to patients who undergo CR after MI are still missing in literature. It would be attractive to evaluate LV vortex features and kinetic energy dissipation before and after a CR program, in order to obtain a further index of LV remodeling and function.

An interesting recent pilot study explored the effects of standard CR with and without transcendental meditation (TM) on CFR assessed by ${ }^{13} \mathrm{~N}$-ammonia PET. For the combined TM group, CFR increased when compared to the combined non-TM group [69]. These results may be applied to the design of controlled clinical trials to definitively test these effects also on CFR assessed by echocardiography.

Even arterial stiffness evaluation finds an interesting application in $C R$ field. In particular, PWV was shown to be decreased in absence of changes of peripheric arterial blood pressure in patients with IHD undergoing a CR program [70-72]. Moreover, a "dose-response" association between the reduction of arterial PWV and the number of CR sessions was observed. The improved ventricular-vascular coupling derived from reduced arterial stiffness could contribute to the better functional capacity and the lower cardiovascular morbidity of patients who undergo CR.

Table 2 illustrates the most commonly collected traditional echocardiographic parameters and the measurements deriving from new ultrasound technologies, which may be assessed before and after a program of CR.

Table 2. Traditional and new echocardiographic measurements to assess before and after a CR program.

\begin{tabular}{|c|c|c|}
\hline Category & Traditional Indexes & New Technologies Indexes \\
\hline $\begin{array}{l}\text { LV dimension and } \\
\text { systolic function }\end{array}$ & $\begin{array}{ll}- & \text { LVEDD, LVESD } \\
- & \text { LVEDV, LVESV } \\
- & \text { LVEF } \\
- & \text {-SVi, COi }\end{array}$ & $\begin{array}{ll}\text { - } & \text { Septal and lateral } S^{\prime} \text { waves } \\
\text { - } & \text { GLS } \\
\text { - } & \text { Radial strain, circumferential } \\
& \text { strain, twist } \\
\text { - } & \text { Vortex properties }\end{array}$ \\
\hline LV diastolic function & $\begin{array}{ll}- & \text { E and A waves } \\
- & \text { E/A ratio } \\
- & \text { E wave DT }\end{array}$ & $\begin{array}{l}\text { - } \quad \text { Lateral and septal } \mathrm{e}^{\prime} \text { waves } \\
\text { - } \quad \text { Average E/e' ratio }\end{array}$ \\
\hline LA dimension and function & $\begin{array}{ll}- & \text { AP diameter } \\
- & \text { LAVi }\end{array}$ & - $\quad$ LA strain \\
\hline $\begin{array}{l}\text { RV dimension and } \\
\text { systolic function }\end{array}$ & $\begin{array}{ll}- & \text { RVD (basal, } \\
& \text { mid-cavity, longitudinal) } \\
- & \text { TAPSE } \\
- & \text { FAC }\end{array}$ & $\begin{array}{l}-\quad S^{\prime} \text { wave } \\
-\quad \text { GLS }\end{array}$ \\
\hline Arterial stiffness & / & PWV \\
\hline
\end{tabular}

CR: cardiac rehabilitation; LV: left ventricular; LVEDD: left ventricular end diastolic diameter; LVESD: left ventricular end systolic diameter; LVEDV: left ventricular end diastolic volume; LVESV: left ventricular end systolic volume; LVEF: left ventricular ejection fraction; SVi: stroke volume index; COi: cardiac output index; GLS: global longitudinal strain; DT: deceleration time; LA: left atrial; AP: antero-posterior; LAVi: left atrial volume index; RV: right ventricular; RVD: right ventricular diameter; TAPSE: tricuspid annulus plane systolic excursion; FAC: fractional area change; PWV: pulsed wave velocity. 


\section{Conclusions}

Standard echocardiography is an essential imaging modality for the assessment of patients affected by IHD, due to its unmatched ability to combine safety and ease of application with depth of diagnostic and prognostic information. The newer ultrasound technologies, which were developed over the past few decades, allowed to better understand the morphofunctional abnormalities occurring in cardiovascular diseases. These technological advancements revealed to be promising to further expand the role of echocardiography as modality of choice in IHD diagnosis, risk stratification, management, and monitoring after cardiac rehabilitation.

Author Contributions: A.D., C.V., F.G. and G.C. participated to study design and coordination; R.S., G.V., and A.D.L. performed the bibliographic research; M.M. provided technical indications about new ultrasound technologies; S.S., E.V., and F.M.S. wrote the different sections of the manuscript; G.I., M.G., and M.P. drew images and tables; E.P. performed the final revision of the manuscript. All authors have read and agreed to the published version of the manuscript.

Funding: This research received no external funding.

Conflicts of Interest: The authors declare no conflict of interest

\section{References}

1. Nowbar, A.N.; Gitto, M.; Howard, J.P.; Francis, D.P.; Al-Lamee, R. Mortality from ischemic heart disease. Circ. Cardiovasc. Qual. Outcomes 2019, 12, e005375. [CrossRef] [PubMed]

2. Knuuti, J.; Wijns, W.; Saraste, A.; Capodanno, D.; Barbato, E.; Funck-Brentano, C.; Prescott, E.; Storey, R.F.; Deaton, C.; Cuisset, T.; et al. 2019 ESC Guidelines for the diagnosis and management of chronic coronary syndromes. Eur. Heart J. 2019, 41, 407-477. [CrossRef] [PubMed]

3. Bansal, M.; Kasliwal, R.R. How do I do it? Speckle-tracking echocardiography. Indian Heart J. 2012, 65, 117-123. [CrossRef] [PubMed]

4. Muraru, D.; Niero, A.; Zanella, H.R.; Cherata, D.; Badano, L.P. Three-dimensional speckle-tracking echocardiography: Benefits and limitations of integrating myocardial mechanics with three-dimensional imaging. Cardiovasc. Diagn. Ther. 2018, 8, 101-117. [CrossRef]

5. Omar, A.M.S.; Bansal, M.; Sengupta, P.P. Advances in echocardiographic imaging in heart failure with reduced and preserved ejection fraction. Circ. Res. 2016, 119, 357-374. [CrossRef]

6. Weidemann, F.; Wacker, C.; Rauch, A.; Bauer, W.R.; Bijnens, B.; Sutherland, G.R.; Ertl, G.; Voelker, W.; Fidler, F.; Strotmann, J. Sequential changes of myocardial function during acute myocardial infarction, in the early and chronic phase after coronary intervention described by ultrasonic strain rate imaging. J. Am. Soc. Echocardiogr. 2006, 19, 839-847. [CrossRef]

7. Cimino, S.; Canali, E.; Petronilli, V.; Cicogna, F.; De Luca, L.; Francone, M.; Sardella, G.; Iacoboni, C.; Agati, L. Global and regional longitudinal strain assessed by two-dimensional speckle tracking echocardiography identifies early myocardial dysfunction and transmural extent of myocardial scar in patients with acute ST elevation myocardial infarction and relatively preserved LV function. Eur. Heart J. Cardiovasc. Imaging 2012, 14, 805-811. [CrossRef]

8. Liu, C.; Li, J.; Ren, M.; Wang, Z.-Z.; Li, Z.-Y.; Gao, F.; Tian, J.-W. Multilayer longitudinal strain at rest may help to predict significant stenosis of the left anterior descending coronary artery in patients with suspected non-ST-elevation acute coronary syndrome. Int. J. Cardiovasc. Imaging 2016, 32, 1675-1685. [CrossRef]

9. Sarvari, S.I.; Haugaa, K.H.; Zahid, W.; Bendz, B.; Aakhus, S.; Aaberge, L.; Edvardsen, T. Layer-specific quantification of myocardial deformation by strain echocardiography may reveal significant CAD in patients with non-ST-segment elevation acute coronary syndrome. JACC Cardiovasc. Imaging 2013, 6, 535-544. [CrossRef]

10. Zhang, L.; Wu, W.-C.; Ma, H.; Wang, H. Usefulness of layer-specific strain for identifying complex CAD and predicting the severity of coronary lesions in patients with non-ST-segment elevation acute coronary syndrome: Compared with Syntax score. Int. J. Cardiol. 2016, 223, 1045-1052. [CrossRef] 
11. Hutyra, M.; Skala, T.; Horak, D.; Kocher, M.; Tüdös, Z.; Zapletalová, J.; Přeček, J.; Louis, A.; Smékal, A.; Taborsky, M. Echocardiographic assessment of global longitudinal right ventricular function in patients with an acute inferior ST elevation myocardial infarction and proximal right coronary artery occlusion. Int. J. Cardiovasc. Imaging 2014, 31, 497-507. [CrossRef] [PubMed]

12. D'Andrea, A.; Radmilovic, J.; Mele, D.; D'Ascenzi, F.; Agricola, E.; Carbone, A.; Iudice, F.L.; Novo, G.; Ancona, F.; Righini, F.M.; et al. Speckle tracking analysis in intensive care unit: A toy or a tool? Echocardiography 2018, 35, 506-519. [CrossRef] [PubMed]

13. Woo, J.S.; Kim, W.-S.; Yu, T.-K.; Ha, S.J.; Kim, S.Y.; Bae, J.-H.; Kim, K.S. Prognostic value of serial global longitudinal strain measured by two-dimensional speckle tracking echocardiography in patients with ST-segment elevation myocardial infarction. Am. J. Cardiol. 2011, 108, 340-347. [CrossRef] [PubMed]

14. Hung, C.-L.; Verma, A.; Uno, H.; Shin, S.-H.; Bourgoun, M.; Hassanein, A.; McMurray, J.J.; Velazquez, E.J.; Kober, L.; Pfeffer, M.A.; et al. Longitudinal and circumferential strain rate, left ventricular remodeling, and prognosis after myocardial infarction. J. Am. Coll. Cardiol. 2010, 56, 1812-1822. [CrossRef] [PubMed]

15. Ersbøll, M.; Valeur, N.; Andersen, M.J.; Mogensen, U.M.; Vinther, M.; Svendsen, J.H.; Moller, J.E.; Kisslo, J.; Velazquez, E.J.; Hassager, C.; et al. Early echocardiographic deformation analysis for the prediction of sudden cardiac death and life-threatening arrhythmias after myocardial infarction. JACC Cardiovasc. Imaging 2013, 6, 851-860. [CrossRef]

16. Antoni, M.L.; Mollema, S.A.; Atary, J.Z.; Borleffs, C.J.W.; Boersma, E.; Van De Veire, N.R.; Holman, E.R.; Van Der Wall, E.E.; Schalij, M.J.; Bax, J.J. Time course of global left ventricular strain after acute myocardial infarction. Eur. Heart J. 2010, 31, 2006-2013. [CrossRef]

17. D'Andrea, A.; Mele, D.; Agricola, E.; Pezzullo, E.; Cameli, M.; Rossi, A.; Esposito, R.; Novo, G.; Mondillo, S.; Montisci, R.; et al. XStrain 4D analysis predicts left ventricular remodeling in patients with recent non-ST-segment elevation myocardial infarction. Int. J. Cardiol. 2016, 206, 107-109. [CrossRef]

18. D'Andrea, A.; Cocchia, R.; Caso, P.; Riegler, L.; Scarafile, R.; Salerno, G.; Golia, E.; Di Salvo, G.; Calabrò, P.; Cappelli-Bigazzi, M.; et al. Global longitudinal speckle-tracking strain is predictive of left ventricular remodeling after coronary angioplasty in patients with recent non-st elevation myocardial infarction. Int. J. Cardiol. 2011, 153, 185-191. [CrossRef]

19. D'Andrea, A.; Caso, P.; Scarafile, R.; Riegler, L.; Salerno, G.; Castaldo, F.; Gravino, R.; Cocchia, R.; Del Viscovo, L.; Limongelli, G.; et al. Effects of global longitudinal strain and total scar burden on response to cardiac resynchronization therapy in patients with ischaemic dilated cardiomyopathy. Eur. J. Heart Fail. 2009, 11, 58-67. [CrossRef]

20. Ersboll, M.K.; Andersen, M.J.; Valeur, N.; Mogensen, U.M.; Waziri, H.; Moller, J.E.; Hassager, C.; Søgaard, P.; Kober, L. The prognostic value of left atrial peak reservoir strain in acute myocardial infarction is dependent on left ventricular longitudinal function and left atrial size. Circ. Cardiovasc. Imaging 2013, 6, 26-33. [CrossRef]

21. Leung, M.; Abou, R.; Van Rosendael, P.J.; Van Der Bijl, P.; Van Wijngaarden, S.E.; Regeer, M.V.; Podlesnikar, T.; Marsan, N.A.; Leung, D.Y.; Delgado, V.; et al. Relation of echocardiographic markers of left atrial fibrosis to atrial fibrillation burden. Am. J. Cardiol. 2018, 122, 584-591. [CrossRef] [PubMed]

22. Pathan, F.; D’Elia, N.; Nolan, M.; Marwick, T.H.; Negishi, K. Normal ranges of left atrial strain by speckle-tracking echocardiography: A systematic review and meta-analysis. J. Am. Soc. Echocardiogr. 2017, 30, 59-70.e8. [CrossRef] [PubMed]

23. D'Andrea, A.; Caso, P.; Romano, S.; Scarafile, R.; Cuomo, S.; Salerno, G.; Riegler, L.; Limongelli, G.; Di Salvo, G.; Romanò, M.; et al. Association between left atrial myocardial function and exercise capacity in patients with either idiopathic or ischemic dilated cardiomyopathy: A two-dimensional speckle strain study. Int. J. Cardiol. 2009, 132, 354-363. [CrossRef] [PubMed]

24. D'Andrea, A.; Caso, P.; Romano, S.; Scarafile, R.; Riegler, L.; Salerno, G.; Limongelli, G.; Di Salvo, G.; Calabrò, P.; Del Viscovo, L.; et al. Different effects of cardiac resynchronization therapy on left atrial function in patients with either idiopathic or ischaemic dilated cardiomyopathy: A two-dimensional speckle strain study. Eur. Heart J. 2007, 28, 2738-2748. [CrossRef] [PubMed]

25. D'Andrea, A.; Scarafile, R.; Riegler, L.; Salerno, G.; Gravino, R.; Cocchia, R.; Castaldo, F.; Allocca, F.; Limongelli, G.; Di Salvo, G.; et al. Right atrial size and deformation in patients with dilated cardiomyopathy undergoing cardiac resynchronization therapy. Eur. J. Heart Fail. 2009, 11, 1169-1177. [CrossRef] 
26. Ancona, R.; Pinto, S.C.; Caso, P.; D’Andrea, A.; Di Salvo, G.; Arenga, F.; Coppola, M.G.; Sellitto, V.; Macrino, M.; Calabro, R. Left atrium by echocardiography in clinical practice: From conventional methods to new echocardiographic techniques. Sci. World J. 2014, 2014, 1-15. [CrossRef]

27. Ancona, R.; Pinto, S.C.; Caso, P.; Di Salvo, G.; Severino, S.; D’Andrea, A.; Calabro, R. Two-dimensional atrial systolic strain imaging predicts atrial fibrillation at 4-year follow-up in asymptomatic rheumatic mitral stenosis. J. Am. Soc. Echocardiogr. 2013, 26, 270-277. [CrossRef]

28. Carluccio, E.; Biagioli, P.; Mengoni, A.; Cerasa, M.F.; Lauciello, R.; Zuchi, C.; Bardelli, G.; Alunni, G.; Coiro, S.; Gronda, E.G.; et al. Left atrial reservoir function and outcome in heart failure with reduced ejection fraction. Circ. Cardiovasc. Imaging 2018, 11, 007696. [CrossRef]

29. Liu, Y.-Y.; Xie, M.; Xu, J.-F.; Wang, X.-F.; Lv, Q.; Lu, X.-F.; Wang, J.; He, L.; Fang, L.-Y.; Zhang, J. Evaluation of Left Atrial Function in Patients with Coronary Artery Disease by Two-Dimensional Strain and Strain Rate Imaging. Echocardiography 2011, 28, 1095-1103. [CrossRef] [PubMed]

30. Othman, K.M.S.; Nassar, A.I.; Fouad, A.; Ramzy, A.A.; Allah, M.F.F.A. Left atrial deformation analysis as a predictor of severity of coronary artery disease. Egypt. Heart J. 2018, 70, 353-359. [CrossRef]

31. Stefanadis, C.; Dernellis, J.; Tsiamis, E.; Toutouzas, P. Effects of pacing-induced and balloon coronary occlusion ischemia on left atrial function in patients with coronary artery disease. J. Am. Coll. Cardiol. 1999, 33, 687-696. [CrossRef]

32. Correale, M.; Totaro, A.; Ieva, R.; Ferraretti, A.; Musaico, F.; Di Biase, M. Tissue Doppler imaging in coronary artery diseases and heart failure. Curr. Cardiol. Rev. 2012, 8, 43-53. [CrossRef] [PubMed]

33. Agarwal, R.; Gosain, P.; Kirkpatrick, J.N.; Alyousef, T.; Doukky, R.; Singh, G.; Umscheid, C.A. Tissue Doppler imaging for diagnosis of coronary artery disease: A systematic review and meta-analysis. Cardiovasc. Ultrasound 2012, 10, 47. [CrossRef] [PubMed]

34. Eek, C.; Grenne, B.; Brunvand, H.; Aakhus, S.; Endresen, K.; Smiseth, O.A.; Edvardsen, T.; Skulstad, H. Postsystolic shortening is a strong predictor of recovery of systolic function in patients with non-ST-elevation myocardial infarction. Eur. J. Echocardiogr. 2011, 12, 483-489. [CrossRef]

35. Hosokawa, H.; Sheehan, F.H.; Suzuki, T. Measurement of postsystolic shortening to assess viability and predict recovery of left ventricular function after acute myocardial infarction. J. Am. Coll. Cardiol. 2000, 35, 1842-1849. [CrossRef]

36. Song, J.-K.; Song, J.-M.; Kang, D.-H.; Haluska, B.; Marwick, T.H. Postsystolic thickening detected by doppler myocardial imaging: A marker of viability or ischemia in patients with myocardial infarction. Clin. Cardiol. 2006, 27, 29-32. [CrossRef]

37. Terkelsen, C.J.; Poulsen, S.H.; Nørgaard, B.L.; Lassen, J.F.; Gerdes, J.C.; Sloth, E.; Nielsen, T.T.; Andersen, H.R.; Egeblad, H. Does Postsystolic motion or shortening predict recovery of myocardial function after primary Percutanous coronary intervention? J. Am. Soc. Echocardiogr. 2007, 20, 505-511. [CrossRef]

38. Brainin, P.; Haahr-Pedersen, S.; Sengeløv, M.; Olsen, F.J.; Fritz-Hansen, T.; Jensen, J.S.; Biering-Sørensen, T. Presence of post-systolic shortening is an independent predictor of heart failure in patients following ST-segment elevation myocardial infarction. Int. J. Cardiovasc. Imaging 2017, 34, 751-760. [CrossRef]

39. Mele, D.; Smarrazzo, V.; Pedrizzetti, G.; Capasso, F.; Pepe, M.; Severino, S.; Luisi, G.A.; Maglione, M.; Ferrari, R. Intracardiac flow analysis: Techniques and potential clinical applications. J. Am. Soc. Echocardiogr. 2019, 32, 319-332. [CrossRef]

40. Agati, L.; Cimino, S.; Tonti, G.; Cicogna, F.; Petronilli, V.; De Luca, L.; Iacoboni, C.; Pedrizzetti, G. Quantitative analysis of intraventricular blood flow dynamics by echocardiographic particle image velocimetry in patients with acute myocardial infarction at different stages of left ventricular dysfunction. Eur. Heart J.-Cardiovasc. Imaging 2014, 15, 1203-1212. [CrossRef] [PubMed]

41. Chan, B.T.; Yeoh, H.K.; Liew, Y.M.; Dokos, S.; Al Abed, A.; Chee, K.H.; Aziz, Y.F.A.; Sridhar, G.S.; Chinna, K.; Lim, E. Quantitative analysis of intraventricular flow-energetics and vortex in ischaemic hearts. Coron. Artery Dis. 2018, 29, 316-324. [CrossRef] [PubMed]

42. Nucifora, G.; Delgado, V.; Bertini, M.; Marsan, N.A.; Van De Veire, N.R.; Ng, A.C.T.; Siebelink, H.-M.J.; Schalij, M.J.; Holman, E.R.; Sengupta, P.P.; et al. Left ventricular muscle and fluid mechanics in acute myocardial infarction. Am. J. Cardiol. 2010, 106, 1404-1409. [CrossRef] [PubMed]

43. Son, J.-W.; Park, W.-J.; Choi, J.-H.; Houle, H.; Vannan, M.A.; Hong, G.-R.; Chung, N. Abnormal left ventricular vortex flow patterns in association with left ventricular apical thrombus formation in patients with anterior myocardial infarction. Circ. J. 2012, 76, 2640-2646. [CrossRef] [PubMed] 
44. Trocino, G. Italian Society of Cardiovascular Echography (SIEC) Consensus Conference on the state of the art of contrast echocardiography. Ital. Heart. J. Off. J. Ital. Fed. Cardiol. 2004, 5, 309-334.

45. Zagatina, A.; Zhuravskaya, N.; Shmatov, D.; Ciampi, Q.; Carpeggiani, C.; Picano, E. Exercise stress echocardiography with $\mathrm{ABCDE}$ protocol in unexplained dyspnoea. Int. J. Cardiovasc. Imaging 2020, 1-9. [CrossRef]

46. Scali, M.C.; Zagatina, A.; Ciampi, Q.; Cortigiani, L.; D'Andrea, A.; Djordjevic-Dikic, A.; Merlo, P.M.; Lattanzi, F.; Simova, I.; Monte, I.P.; et al. The functional meaning of B-Profile during stress lung ultrasound. JACC Cardiovasc. Imaging 2019, 12, 928-930. [CrossRef]

47. Gan, L.-M.; Svedlund, S.; Wittfeldt, A.; Eklund, C.; Gao, S.; Matejka, G.; Jeppsson, A.; Albertsson, P.; Omerovic, E.; Lerman, A. Incremental value of transthoracic doppler echocardiography-assessed coronary flow reserve in patients with suspected myocardial ischemia undergoing myocardial perfusion Scintigraphy. J. Am. Heart Assoc. 2017, 6, e004875. [CrossRef]

48. Haraldsson, I.; Gan, L.-M.; Svedlund, S.; Wittfeldt, A.; Råmunddal, T.; Angerås, O.; Albertsson, P.; Matejka, G.; Omerovic, E. Non-invasive evaluation of coronary flow reserve with transthoracic Doppler echocardiography predicts the presence of significant stenosis in coronary arteries. Int. J. Cardiol. 2014, 176, 294-297. [CrossRef]

49. Rahmani, M.; Cruz, R.P.; Granville, D.J.; McManus, B.M. Allograft Vasculopathy versus atherosclerosis. Circ. Res. 2006, 99, 801-815. [CrossRef]

50. Sade, L.E.; Eroğlu, S.; Yuce, D.; Bircan, A.; Pirat, B.; Sezgin, A.; Aydınalp, A.; Muderrisoglu, H.; Bircan, A.; Aydinalp, A. Follow-up of heart transplant recipients with serial echocardiographic coronary flow reserve and Dobutamine stress echocardiography to detect cardiac allograft Vasculopathy. J. Am. Soc. Echocardiogr. 2014, 27, 531-539. [CrossRef]

51. Feola, M.; Testa, M.; Ferreri, C.; Rosso, G.; Rossi, A.; Ruocco, G. The analysis of arterial stiffness in heart failure patients in comparison with healthy subjects and patients with cardiovascular risk factors. J. Clin. Med. 2019, 8, 1721. [CrossRef] [PubMed]

52. Ikonomidis, I.; Makavos, G.; Lekakis, J.P. Arterial stiffness and coronary artery disease. Curr. Opin. Cardiol. 2015, 30. [CrossRef] [PubMed]

53. Mitchell, G.F.; Hwang, S.-J.; Vasan, R.S.; Larson, M.G.; Pencina, M.J.; Hamburg, N.M.; Vita, J.A.; Levy, D.; Benjamin, E.J. Arterial stiffness and cardiovascular events: The Framingham heart study. Circulation 2010, 121, 505-511. [CrossRef] [PubMed]

54. Vlachopoulos, C.; Aznaouridis, K.; Stefanadis, C. Prediction of cardiovascular events and all-cause mortality with arterial stiffness: A systematic review and meta-analysis. J. Am. Coll. Cardiol. 2010, 55, 1318-1327. [CrossRef]

55. Kaneko, H.; Yajima, J.; Oikawa, Y.; Matsuno, S.; Funada, R.; Tanaka, S.; Fukamachi, D.; Suzuki, S.; Aizawa, T.; Yamashita, T. Role of arterial stiffness and impaired renal function in the progression of new coronary lesions after percutaneous coronary intervention. Cardiovasc. Interv. Ther. 2012, 28, 56-62. [CrossRef]

56. Nakamura, M.; Yamashita, T.; Yajima, J.; Oikawa, Y.; Sagara, K.; Koike, A.; Kirigaya, H.; Nagashima, K.; Sawada, H.; Aizawa, T.; et al. Brachial-ankle pulse wave velocity as a risk stratification index for the short-term prognosis of type 2 diabetic patients with coronary artery disease. Hypertens. Res. 2010, 33, 1018-1024. [CrossRef]

57. Regnault, V.; Lagrange, J.; Pizard, A.; Safar, M.E.; Fay, R.; Pitt, B.; Challande, P.; Rossignol, P.; Zannad, F.; Lacolley, P. Opposite predictive value of pulse pressure and aortic pulse wave velocity on heart failure with reduced left ventricular ejection fraction: Insights from an Eplerenone Post-Acute Myocardial Infarction Heart Failure Efficacy and Survival Study (EPHESUS) substudy. Hypertension 2014, 63, 105-111. [CrossRef]

58. Valkeinen, H.; Aaltonen, S.; Kujala, U.M. Effects of exercise training on oxygen uptake in coronary heart disease: A systematic review and meta-analysis. Scand. J. Med. Sci. Sports 2010, 20, 545-555. [CrossRef]

59. Taylor, R.S.; Brown, A.; Ebrahim, S.; Jolliffe, J.; Noorani, H.; Rees, K.; Skidmore, B.; Stone, J.; Thompson, D.R.; Oldridge, N. Exercise-based rehabilitation for patients with coronary heart disease: Systematic review and meta-analysis of randomized controlled trials. Am. J. Med. 2004, 116, 682-692. [CrossRef]

60. Giannuzzi, P.; Temporelli, P.; Corrà, U.; Tavazzi, T. Antiremodeling effect of long-term exercise training in patients with stable chronic heart failure results of the exercise in left ventricular dysfunction and chronic heart failure (ELVD-CHF) trial. ACC Curr. J. Rev. 2003, 12, 43. [CrossRef]

61. Heran, B.S.; Chen, J.M.; Ebrahim, S.; Moxham, T.; Oldridge, N.; Rees, K.; Thompson, D.R.; Taylor, R. Exercise-based cardiac rehabilitation for coronary heart disease. Cochrane Database Syst. Rev. 2011, 001800. [CrossRef] 
62. Petrovic, M.T.; Djordjevic-Dikic, A.; Giga, V.; Boskovic, N.; Vukcevic, V.; Cvetic, V.; Mladenovic, A.; Radmili, O.; Markovic, Z.; Dobric, M.; et al. The coronary ARteriogenesis with combined Heparin and EXercise therapy in chronic refractory Angina (CARHEXA) trial: A double-blind, randomized, placebo-controlled stress echocardiographic study. Eur. J. Prev. Cardiol. 2020, 8. [CrossRef]

63. Haykowsky, M.J.; Scott, J.; Esch, B.; Schopflocher, D.P.; Myers, J.; Paterson, I.; Warburton, D.E.; Jones, L.W.; Clark, A.M. A meta-analysis of the effects of exercise training on left ventricular remodeling following myocardial infarction: Start early and go longer for greatest exercise benefits on remodeling. Trials 2011, 12, 92. [CrossRef] [PubMed]

64. Gonzalez-Represas, A.; Mourot, L. Stroke volume and cardiac output measurement in cardiac patients during a rehabilitation program: Comparison between tonometry, impedancemetry and echocardiography. Int. J. Cardiovasc. Imaging 2019, 36, 447-455. [CrossRef]

65. McGregor, G.; Stöhr, E.J.; Oxborough, D.; Kimani, P.K.; Shave, R. Effect of exercise training on left ventricular mechanics after acute myocardial infarction-an exploratory study. Ann. Phys. Rehabil. Med. 2018, 61, 119-124. [CrossRef]

66. Trachsel, L.; David, L.; Gayda, M.; Henri, C.; Hayami, D.; Thorin-Trescases, N.; Thorin, É.; Blain, M.; Cossette, M.; Lalongé, J.; et al. The impact of high-intensity interval training on ventricular remodeling in patients with a recent acute myocardial infarction-A randomized training intervention pilot study. Clin. Cardiol. 2019, 42, 1222-1231. [CrossRef]

67. Malfatto, G.; Revera, M.; Branzi, G.; Ciambellotti, F.; Giglio, A.; Blengino, S.; Oldani, M.; Facchini, C.; Parati, G.; Facchini, M. A brief period of intensive cardiac rehabilitation improves global longitudinal strain and diastolic function after a first uncomplicated myocardial infarction. Acta Cardiol. 2017, 72, $284-291$. [CrossRef]

68. Acar, R.D.; Bulut, M.; Ergun, S.; Yesin, M.; Alıcı, G.; Akcakoyun, M.; Alici, G. Effect of cardiac rehabilitation on left atrial functions in patients with acute myocardial infarction. Ann. Phys. Rehabil. Med. 2014, 57, 105-113. [CrossRef]

69. Bokhari, S.; Schneider, R.H.; Salerno, J.W.; Rainforth, M.V.; Gaylord-King, C.; Nidich, S.I. Effects of cardiac rehabilitation with and without meditation on myocardial blood flow using quantitative positron emission tomography: A pilot study. J. Nucl. Cardiol. 2019, 1-12. [CrossRef]

70. Laskey, W.K.; Siddiqi, S.; Wells, C.; Lueker, R. Improvement in arterial stiffness following cardiac rehabilitation. Int. J. Cardiol. 2013, 167, 2734-2738. [CrossRef]

71. Oliveira, N.L.; Ribeiro, F.; Silva, G.; Alves, A.J.; Silva, N.; Guimarães, J.T.; Teixeira, M.; Oliveira, J. Effect of exercise-based cardiac rehabilitation on arterial stiffness and inflammatory and endothelial dysfunction biomarkers: A randomized controlled trial of myocardial infarction patients. Atherosclerosis 2015, 239, 150-157. [CrossRef] [PubMed]

72. Cieslik-Guerra, U.; Wierzbowska-Drabik, K.; Trzos, E.; Kaminski, M.; Kotas, R.; Rechcinski, T.; Kasprzak, J.; Napieralski, A.; Kurpesa, M. Cardiac rehabilitation reduces arterial stiffness independently of the coexistence of arterial hypertension (forever study). J. Hypertens. 2019, 37, e287. [CrossRef]

(C) 2020 by the authors. Licensee MDPI, Basel, Switzerland. This article is an open access article distributed under the terms and conditions of the Creative Commons Attribution (CC BY) license (http://creativecommons.org/licenses/by/4.0/). 